\title{
Expression of MAdCAM-1 and PNAd in Inflamma- tory and MALT Lymphoma Tissues of Ocular Adnexa, Thyroid, Salivary Gland and Lung
}

\author{
Yi-Xuan Liu, Nobuya Ohara, Tadashi Yoshino, Gui-Shan Jin and Tadaatsu Akagi
}

Mucosa-associated lymphoid tissue (MALT) lymphomas usually arise from acquired MALT induced by chronic inflammation or autoimmune processes. In MALT of the gastrointestinal tract lymphocyte homing mechanisms operate primarily through interactions between integrin, expressed on mucosal lymphocytes, and MAdCAM-1, expressed on endothelium of high endothelial venules (HEV). In the present study, the expression of MAdCAM-1 and peripheral lymph node vascular addressin (PNAd) was examined immunohistochemically in normal, inflamed and MALT lymphoma tissues of various organs. It was shown that MAdCAM-1 was expressed on HEV in the gastrointestinal tract and thyroid that are inflamed or affected with MALT lymphomas, but not in the ocular adnexa, lung, and salivary gland. In contrast, PNAd was consistently expressed in all of the inflammatory or lymphomatous lesions examined, but not in the normal tissues. Expression of MAdCAM-1 on HEV may play an important role in lymphocyte migration at sites of chronic inflammation or MALT lymphoma of the gastrointestinal tract and thyroid. In other organs, PNAd may have the greater role.

Key words MAdCAM-1, PNAd, chronic inflammation, MALT Lymphoma

Extranodal marginal zone B-cell lymphoma of mucosa-associated lymphoid tissue (MALT) is a distinct type of low-grade B-cell lymphoma with unique histopathological and clinical features ${ }^{1,2}$. MALT lymphomas arise from acquired MALT which develops at sites of chronic inflammation in response to either infection, such as Helicobacter pylori gastritis, or autoimmune conditions, such as Hashimoto's thyroiditis or Sjögren's syndrome $e^{2-5}$. MALT lymphomas tend to remain localized to their site of origin for extremely long periods without distant dissemination ${ }^{6}$. Lymphocyte homing mechanisms may be at least partly related to this biological behavior.

Most mature lymphocytes migrate continuously form blood to tissue then back to blood. The lymphocyte homing is largely determined by various

Received: Mar 4, 2003

Revised: Jul 13, 2003

Accepted : Jul 22, 2003

Department of Pathology, Okayama University Graduate School of Medicine and Dentistry, Okayama, Japan

Address correspondence and reprint requests to Tadaatsu Akagi, Department of Pathology, Okayama University Graduate School of Medicine and Dentistry Shikata-cho, 2-5-1, Okayama, 700-8558, Japan homing receptors and their vascular ligands. Homing of circulating lymphocytes from blood to both normal and inflammatory tissues is partly regulated by highly specific interactions between the cell surface homing receptors of lymphocytes and their endothelial ligands expressed on high endothelial venules (HEV) of the peripheral lymph nodes, MALT, and sites of chronic inflammation ${ }^{7-9}$. Lymphocyte homing to Peyer's patches and mesenteric lymph nodes is mediated through interactions between $\alpha_{4} \beta_{7}$ integrin expressed on mucosal lymphocytes and mucosal vascular addressin cell adhesion molecule-1 (MAdCAM-1) ${ }^{10,11}$. In the previous study, we examined expression of $\alpha_{4} \beta_{7}$ integrin and MAdCAM-1 in MALT lymphomas and revealed that neoplastic cells in the gastrointestinal low-grade MALT lymphomas consistently express $\alpha_{4} \beta_{7}$ integrin and tend to lose its expression after high-grade progression ${ }^{12}$. Preliminary study on MAdCAM-1 expression also revealed consistent expression on HEV in the gastric mucosa of chronic gastritis and MALT lymphoma ${ }^{12}$. In mice and rats it has been reported that MAdCAM-1 is expressed on HEV in normal and chronically inflamed pancreas and in intestinal mucosa and submucosa, but 


\section{Y. Liu et al.}

not in the normal thymus, esophagus, salivary gland, lung, liver, bladder, skin, or inflamed lacrimal gland $^{13-15}$. Recent studies in humans have revealed that MAdCAM-1 is expressed in the intestinal tract, but there is little data regarding expression in other organs. In this study, we examined expression of peripheral lymph node vascular addressin (PNAd) known to mediate lymphocyte migration to the peripheral lymph node and to sites of inflammation $^{9}$. We also examined the expression of MAdCAM-1 in the human ocular adnexa, salivary gland, thyroid gland and lung in the normal, inflammatory or lymphomatous state by the immunohistochemical method.

Deparaffinized tissue sections were obtained from 58 cases of low-grade MALT lymphoma (18 stomach, 12 ocular adnexa, 14 thyroid, 7 salivary gland and 7 lung) and 24 cases of chronic inflammation (9 thyroid and 15 salivary gland). The sections were immunostained by the indirect immunoperoxi- dase method using dextran polymer-conjugated secondary antibody labeled with peroxidase (EnVision +, DAKO Japan, Kyoto) as described previously ${ }^{12}$. Anti human MAdCAM-1 (10A6) and PNAd (MECA79) were used as the primary monoclonal antibodies.

Immunohistochemical staining showed that MAdCAM-1 was expressed consistently on HEV in the gastric mucosa of lymphomatous lesions of gastric MALT lymphoma and chronic gastritis. In the thyroid, MAdCAM-1 was selectively expressed on endothelial cells of HEV in the lymphomatous lesions of half the cases of thyroidal MALT lymphoma and in the inflamed tissues of two-thirds of the cases of chronic thyroiditis, including $\mathrm{Ha}$ shimoto's thyroiditis (Fig. 1, A, B; Table 1). Normal thyroid tissues lacked MAdCAM-1 expression. Although their rates of positive expression were lower than that in gastrointestinal, low-grade MALT lymphomas. The lymphocyte homing mech-
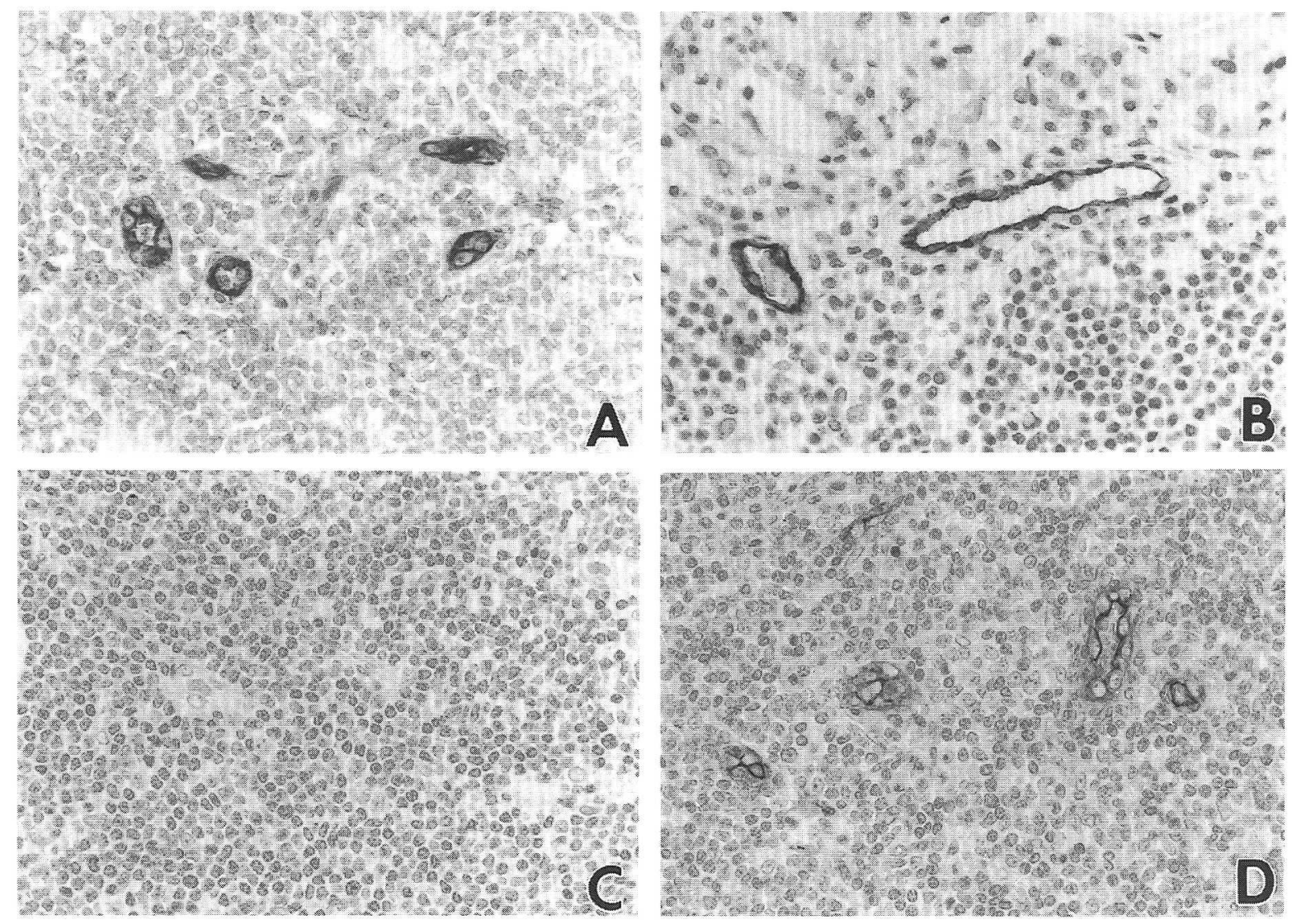

Fig. 1. Immunohistochemical staining for MAdCAM-1 and PNAd.

(A) MALT lymphoma of the thyroid. MAdCAM-1. $\times 280$.

(B) Hashimoto's thyroiditis. MAdCAM-1. $\times 290$.

(C) MALT lymphoma of the salivary gland. MAdCAM-1. $\times 250$.

(D) MALT lymphoma of the salivary gland. PNAd. $\times 250$ 
Table 1 Expression of MAdCAM-1 and PNAd in stomach, ocular adnexa, thyroid, salivary gland and lung

\begin{tabular}{|c|c|c|c|}
\hline Organ & Disease & MAdCAM-1 & PNAd \\
\hline \multirow[t]{2}{*}{ Stomach } & Low-grade MALT lymphoma & $18 / 18^{*}$ & $18 / 18$ \\
\hline & Chronic gastritis & $19 / 19$ & $14 / 19$ \\
\hline \multirow[t]{3}{*}{ Ocular adnexa } & Low-grade MALT lymphoma & $0 / 12$ & $12 / 12$ \\
\hline & Reactive lymphoid hyperplasia & $0 / 5$ & $5 / 5$ \\
\hline & Normal mucosa & $0 / 5$ & $0 / 5$ \\
\hline \multirow[t]{3}{*}{ Thyroid } & Low-grade MALT lymphoma & $7 / 14$ & $14 / 14$ \\
\hline & Chronic thyroiditis & $6 / 9$ & $9 / 9$ \\
\hline & Normal mucosa & $0 / 9$ & $0 / 9$ \\
\hline \multirow[t]{3}{*}{ Salivary gland } & Low-grade MALT lymphoma & $0 / 7$ & $7 / 7$ \\
\hline & Chronic sialadenitis & $0 / 15$ & $13 / 15$ \\
\hline & Normal mucosa & $0 / 15$ & $0 / 15$ \\
\hline \multirow[t]{4}{*}{ Lung } & Low-grade MALT lymphoma & $0 / 7$ & $6 / 7$ \\
\hline & Nonspecific interstitial pneumonia & $0 / 5$ & $2 / 4$ \\
\hline & Reactive lymphoid hyperplasia & $0 / 1$ & $1 / 1$ \\
\hline & Normal pulmonary tissue & $0 / 5$ & $0 / 5$ \\
\hline
\end{tabular}

*, This data has been reported in reference 12 .

anism, through interaction of $\alpha_{4} \beta_{7}$ integrin and MAdCAM-1, could be related to the biological behavior of MALT lymphoma in the thyroid, as is the case with gastrointestinal expression. In contrast, the venular endothelium of the ocular adnexa, lung, and salivary gland never expressed MAdCAM1 , even at the site of normal tissues and inflamed or lymphomatous lesions (Fig. 1, C). On the other hand, PNAd was expressed consistently in all the inflammatory or lymphomatous lesions that we examined (Fig. 1, D) but not in normal tissues of the ocular adnexa, thyroid gland, salivary gland and lung. This means that PNAd may play a role in lymphocyte homing to the inflamed lesions and in biological behavior of lymphoma cells in MALT lymphoma tissues of these organs.

MAdCAM-1 is important in regulating lymphocyte-trafficking to (gastrointestinal) mucosal sites. And MALT lymphoma cells are thought to originate from acquired chronically inflammatory lesions. Interestingly, MALT lymphomas often form multiple lesions in a single organ, such as the stomach and colorectum. We suppose that this multiplicity is closely related to the expression of adhesion molecules, because neighboring lymph nodes are not usually involved through lymphoma cells. Moreover, we previously reported on the clinicopathological character of multi-organ MALT lymphomas and described frequent MALT lymphoma migration (metastases) to MALT organs without lymph node involvement ${ }^{16}$. This also suggests that MALT lymphoma movement depends on organ-specific adhesion systems.

While the homing receptors $\alpha_{4} \beta_{7}$ integrin/ MAdCAM-1 for the gastrointestinal tract and Lselectin/PNAd for the peripheral lymph nodes have been identified, details are sparse regarding which adhesion receptors are actually used by lymphocytes of MALT organs and peripheral lymph nodes. The $\alpha_{4} \beta_{7}$ integrin is widely expressed by leukocyte subsets in the blood, organized lymphoid tissue, intestinal lamina propria ${ }^{17-22}$ but do not play a major role in homing of lymphocytes in the lacrimal glands, thyroid, and lung in inflammation or MALT lymphoma ${ }^{12,14,23-25}$. L-selectin regulates lymphomyte homing to the peripheral lymph node and lacrimal glands ${ }^{9,14}$, but occasionally positive in normal salivary gland, primary Sjögren's syndrome and thyroid MALT lymphoma ${ }^{12,26}$. In the lung, expression of L-selectin varies according to the stimuli used for initiating inflammation ${ }^{23-25,27,28}$.

In conclusion, it has been shown that human MAdCAM-1 preferentially acts as a vascular addressin for lymphocytes, not only in the gastrointestinal tract, but also in the thyroid gland, and that the lymphocyte homing mechanism may affect the biological behavior of MALT lymphoma cells in these organs through an interaction between MAdCAM-1 and $\alpha_{4} \beta_{7}$ integrin. PNAd is expressed more ubiquitously on venular endothelium at the site of inflammation and may be partly related to the biology of MALT lymphoma arising from the organs other than the gastrointestinal tract and thyroid. 


\section{ACKNOWLEDGMENTS}

We thank Dr. M. J. Briskin of LeukoSite Inc. and Dr. E. C. Butcher of Stanford University for the generous gifts of monoclonal antibody MAdCAM-1 (10A6) and monoclonal antibody PNAd (MECA 79), respectively.

\section{REFERENCES}

1 Isaacson PG. Mucosa-associated lymphoid tissue lymphoma. Semin Hematol 36 : 139-147, 1999

2 Zucca E, Bertoni F, Roggero E, Cavalli F. The gastric marginal zone B-cell lymphoma of MALT type. Blood 96 : 410-419, 2000

3 Isaacson PG. Gastric lymphoma and Helicobacter pylori. N Engl J Med 330: 1310-1311, 1994

4 Hyjek E, Smith WJ, Isaacson PG. Primary B-cell lymphoma of salivary glands and its relationship to myoepithelial sialadenitis. Hum Pathol 19: 766776,1988

5 Hyjek E, Isaacson PG. Primary B-cell lymphoma of the thyroid and its relationship to Hashimoto's thyroiditis. Hum Pathol 19: 1315-1326, 1988

6 Krol AD, Hermans J, Kramer MH, Kluin PM, Kluin-Nelemans HC, Blok P, Heering KJ, Noordijk EM, Han van Krieken J. Gastric lymphomas compared with lymph node lymphomas in a population-based registry differ in stage distribution and dissemination patterns but not in patient survival. Cancer 79: 390-397, 1997

7 Carlos TM, Harlan JM. Leukocyte-endothelial adhesion molecules. Blood 84 : 2068-2101, 1994

8 Butcher EC, Picker LJ. Lymphocyte homing and homeostasis. Science 272: 60-66, 1996

9 Picker LJ, Butcher EC. Physiological and molecular mechanisms of lymphocyte homing. Ann Rev Immunol. 10: 561-591, 1992

10 Berlin C, Berg EL, Briskin MJ, Andrew DP, Kilshaw PJ, Holzmann B, Weissman IL, Hamann A, Butcher EC. $\alpha_{4} \beta_{7}$ integrin mediates lymphocyte binding to the mucosal vescular addressin MAdCAM-1. Cell 74: 185-195, 1993

11 Erle DJ, Briskin MJ, Butcher EC, Garcia-Pardo A, Lazarovits AI, Tidswell M. Expression and function of the MAdCAM-1 receptor, integrin $\alpha_{4} \beta_{7}$, on human leukocytes. J Immunol 153 : 517-528, 1994

12 Liu Y-X, Yoshino T, Ohara N, Oka T, Jin Z-S, Hayashi K, Akagi T. Loss of expression of $\alpha_{4} \beta_{7}$ integrin and $\mathrm{L}$-selectin is associated with high-grade progression of low-grade MALT lymphoma. Mod Pathol 14: 798-805, 2001

13 Briskin M, Winsor-Hines D, Shyjan A, Cochran N, Bloom S, Wilson J, McEvoy LM, Butcher EC,
Kassam N, Mackay CR, Newman W, Ringler DJ. Human mucosal addressin cell adhesion molecule-1 is preferentially expressed in intestinal tract and associated lymphoid tissue. Am J Pathol 151: 97110, 1997

14 Mikulowska-Mennis A, Xu B, Berberian JM, Michie SA. Lymphocyte migration to inflamed lacrimal glands is mediated by vascular cell adhesion molecule-1/ $\alpha_{4} \beta_{1}$ integrin, peripheral nodeaddressin/L-selectin, and lymphocyte functionassociated antigen-1 adhesion pathways. Am J Pathol 159: 671-681, 2001

15 Iizuka T, Tanaka T, Suematsu M, Miura S, Watanabe T, Koike R, Ishimura Y, Ishii H, Miyasaka N, Miyasaka M. Stage-specific expression of mucosal addressin cell adhesion molecule-1 during embryogenesis in rats. J Immunol 164 : 2463-2471, 2000

16 Yoshino T, Ichimura K, Mannami T, Takase S, Ohara N, Okada H, Akagi T. Multiple organ mucosa-associated lymphoid tissue lymphoma often involve the intestine. Cancer 91: 346-353, 2001

17 Erle DJ, Briskin MJ, Butcher EC, Garcia Pardo A, Lazarovits AI, Tidswell M. Expression and function of the MAdCAM-1 receptor, integrin $\alpha_{4} \beta_{7}$, on human leukocytes. J Immunol 153 : 517-528, 1994

18 Schweighoffer T, Tanaka Y, Tidswell M, Erle DJ, Horgan KJ, Ginther Luce GE, Lazarovits AI, Buck $\mathrm{D}$, Shaw S. Selective expression of integrin $\alpha_{4} \beta_{7}$ on a subset of human $\mathrm{CD} 4+$ memory $\mathrm{T}$ cells with hallmarks of gut-tropism. J Immunol 151 : 717-729, 1993

19 Postigo AA, Sánchez-Mateos P, Lazarovits AI, Sánchez-Madrid F, de Landázuri MO. $\alpha_{4} \beta_{7}$ integrin mediate $\mathrm{B}$ cell binding to fibronectin and vascular cell adhesion molecule 1: expression and function of $\alpha_{4}$ integrins on human B lymphocytes. J Immunol 151: 2471-2483, 1993

20 Tiisala S, Paavonen T, Renkonen R. $\alpha \mathrm{E} \beta_{7}$ and $\alpha_{4} \beta_{7}$ integrins associated with intraepithelial and mucosal homing, respectively, are expressed on macrophages. Eur J Immunol 25: 411-417, 1995

21 Farstad IN, Halstensen TS, Lazarovits AI, Norstein J, Fausa O, Brandtzaeg P. Human intestinal B-cell blasts and plasma cells express the mucosal homing receptor integrin $\alpha_{4} \beta_{7}$ Scand J Immunol 42: 662 672, 1995

22 Farstad IN, Halstensen TS, Kvale D, Fausa O, Brandtzaeg P. Topographic distribution of homing receptors of $\mathrm{B}$ and $\mathrm{T}$ cells in human gut-associated lymphoid tissue. Relation of L-selectin and integrin $\alpha_{4} \beta_{7}$ to naive and memory phenotypes. Am J Pathol 150: 187-199, 1997

23 Picker LJ, Martin RJ, Trumble A, Newman LS, Collins PA, Bergstresser PR, Leung DYM. Differen- 


\section{Expression of MAdCAM-1 and PNAd}

tial expression of lymphocyte homing receptors by human memory/effector $\mathrm{T}$ cells in pulmonary versus cutaneous immune effector sites. Eur J Immunol. 24 : 1269-1277, 1994

24 Abitorabi MA, Mackay CR, Jerome EH, Osorio O, Butcher EC, Erle DJ. Differential expression of homing molecules on recirculation lymphocytes from sheep gut, peripheral, and lung lymph. J Immunol. 156: 3111-3117, 1996

25 Michie SA, Streeter PR, Bolt PA, Butcher EC, Picler LJ. The human peripheral lymph node vascular addressin. An inducible endothelial antigen involved in lymphocyte homing. Am J Pathol. 143 : 1688-1698, 1993

26 Aziz KE, McCluskey PJ, Wakefield D. Expression of selectins (CD62 E, L, P) and cellular adhesion molecules in primary Sjögren's syndrome: questions to immunoregulation. Clin Immunol Immunopathol. 80: 55-66, 1996

27 Hamaguchi Y, Nishizawa Y, Yasui M, Hasegawa M, Kaburagi Y, Komura K, Nagaoka T, Saito E, Shimada Y, Takehara K, Kadono T, Steeber DA, Tedder TF, Sato S. Intercellular adhesion molecule1 and L-selectin regulate bleomycin-induced lung fibrosis. Am J Pathol. 161: 1607-1618, 2002

28 Fiscus LC, Van Herpen J, Steeber DA, Tedder TF, Tang ML. L-selectin is required for the development of airway hyperresponsiveness but not airway inflammation in a murine model of asthma. $\mathbf{J}$ Allergy Clin Immunol. 107 : 1019-1024, 2001 